\section{Estratégias na reforma psiquiátrica no município de Barbacena: a cooperação entre gestor público e 0 terceiro setor}

\section{Strategies for} psychiatric reform in Barbacena municipality: cooperation between a public authority and the third sector

Lys Teixeira de Alvarenga

Universidade Federal do Rio de Janeiro Instituto de Psiquiatria - Ipub/UFRJ Instituto Municipal Nise da Silveira/IMNS Rua Ramiro Magalhães, 521 - Engenho de Dentro 20730-460 Rio de Janeiro - RJ - Brasil lysalvarenga@hotmail.com

Cristiane de Oliveira Novaes

Doutoranda em Saúde Pública e Meio Ambiente da Escola Nacional de Saúde Pública/Fiocruz Coordenadora de pesquisa do Pólo Interdisciplinar

na Área do Envelhecimento/Universidade Federal de Juiz de Fora

Rua Severino Meirelles, 260 - Passos

36036-330 Juiz de Fora - MG - Brasil crisufjf@hotmail.com
ALVARENGA, Lys Teixeira de; NOVAES, Cristiane de Oliveira. Estratégias na reforma psiquiátrica no município de Barbacena: a cooperação entre gestor público e o terceiro setor. História, Ciências, Saúde Manguinhos, Rio de Janeiro, v.14, n.2, p.571-593, abr.-jun. 2007.

Este estudo analisa a relação de cooperação firmada no município de Barbacena (MG) entre gestor público e uma instituição do terceiro setor, na construção e gestão de residências assistidas, uma estratégia de desinstitucionalização no contexto da reforma psiquiátrica brasileira. Mostra que essa experiência de cooperação segue a tendência de inovação na modalidade de gestão do setor saúde, indicando uma preocupação pela preservação das diretrizes da reforma psiquiátrica.

PALAVRAS-CHAVE: reforma psiquiátrica; estratégia; cooperação; gestor público; terceiro setor; Brasil.

ALVARENGA, Lys Teixeira de; NOVAES, Cristiane de Oliveira. Strategies for psychiatric reform in Barbacena municipality: cooperation between a public authority and the third sector. História, Ciências, SaúdeManguinhos, Rio de Janeiro, v.14, n.2, p.571-593, Apr.-June 2007.

This study analyzes the cooperation set up in Barbacena municipality, Minas Gerais state, between a public authority and a third sector institution for building and managing assisted living residences as part of a

deinstitutionalization strategy within the overall context of psychiatry reform in Brazil. It shows that this experiment is part of a trend towards innovative health care management, and indicates a will to preserve the principles of psychiatric reform.

KEYWORDS: psychiatric reform; strategy; cooperation; public authority; third sector; Brazil. 
$\mathrm{O}$

processo de reforma psiquiátrica no Brasil é entendido como um conjunto de transformações políticas, administrativas, jurídicas, sociais e culturais, tendo como referência a desinstitucionalização (Amarante, 1995) que ocorreu em fins da década de 1970 e início da seguinte, paralelamente ao movimento de abertura política e de redemocratização do país. Engendrando uma luta pela desinstitucionalização da loucura e a construção de uma rede de atenção integral à saúde mental, em substituição ao sistema hospitalocêntrico, pode-se identificar no país uma série de iniciativas promovidas sobretudo por governos locais, que intervêm de forma decisiva e resolutiva na reforma psiquiátrica brasileira, por meio de trabalhos práticos de implantação de novas políticas e experiências de atenção à saúde mental.

Norteado pelos pressupostos dessa reforma, o município de Barbacena (MG) tem empreendido iniciativas de ordem técnica e política como a criação de serviços, estratégias sanitárias e dispositivos sociais de atenção e cuidados à saúde mental, traduzidas no desenvolvimento de uma rede de atenção substitutiva do hospital psiquiátrico, bem como de um processo de construção de uma nova realidade em torno da loucura e do louco. Essas mudanças, desencadeadas a partir da década de 1990, referem-se à política, aos paradigmas, aos serviços, à capacitação de pessoas, aos modos de atenção à saúde mental e à relação da sociedade com o 'louco'.

Nesse contexto de questionamento, mudanças e rupturas com saberes e práticas instituídos pela psiquiatria e recusa da relação excludente da sociedade com o louco, tornam-se imperativos os processos de abertura no âmbito político, técnico e administrativo, de forma a mobilizar diferentes atores sociais, articulando e comprometendo os diversos segmentos da sociedade. A inclusão de novos atores na formulação, implementação e no controle das políticas na esfera local, bem como a redefinição da esfera pública no campo das políticas sociais ocasionaram a modificação na relação entre Estado e sociedade (Fagundes, 1992). Discutir, então, a ampliação do leque de atores envolvidos nas questões de políticas públicas e no estabelecimento de cooperação entre Estado e sociedade torna-se imprescindível, sobretudo ao abordarmos políticas e ações em saúde mental.

O presente estudo veio à luz por se acreditar que a avaliação das estratégias usadas pelo município no processo de reforma psiquiátrica local é importante para novas construções e formulações no campo da saúde mental - para o próprio município e para outras localidades -, além de servir de avaliação das políticas e ações em andamento. A reflexão sobre a problemática surgiu do acompanhamento de um caso particular: a decisão pela qual o Departamento Municipal de Saúde Pública de Barbacena (Demasp) buscou uma relação de cooperação com uma instituição do terceiro setor 
${ }^{1}$ No decorrer deste trabalho dar-se-á prioridade à expressão 'residência assistida', em vez de 'serviço residencial terapêutico', por se considerar tais casas dispositivos sociais da reforma psiquiátrica, devendo ser compreendidas, em especial, valendose da noção de residencialidade. Esta última exprime mais que a proposta terapêutica desses dispositivos, constituindo-se primeiramente como espaço de moradia, de trocas.
(Instituto José Luiz Ferreira) no âmbito da reforma psiquiátrica, mais especificamente no das residências assistidas. O estudo procurou, dessa forma, realizar uma análise dos determinantes desse caso e entender os mecanismos sobre os quais ele se apóia, bem como seus impactos e efeitos.

Cabe ressaltar que os 'serviços residenciais' se delineiam como um projeto avançado no processo da reforma psiquiátrica no Brasil, como novo dispositivo em saúde mental (Milagres, 2002), situado entre a assistência e a moradia. Esse dispositivo acolhe pacientes considerados crônicos e institucionalizados, egressos de longas internações psiquiátricas e que não possuem suporte social e laço familiar, portanto uma clientela singular que faz refletir sobre estratégias de inserção social.

A implantação das residências assistidas ${ }^{1}$ na rede de saúde mental substitutiva se deu a partir das portarias 106/00 e 1.220/00, do Ministério da Saúde, que determinaram as regras e o financiamento específico para tal dispositivo. Considerando esse eixo de trabalho, podemos apontar outras experiências nacionais, como a dos municípios do Rio de Janeiro (RJ), Porto Alegre e Bagé (RS) e Campinas (SP), pioneiros nos programas de criação de lares abrigados durante a década de 1990 (Milagres, 2002).

Todavia, antes de entrarmos na discussão sobre o objeto desta pesquisa, faz-se necessária uma incursão pela configuração do Estado contemporâneo e pela redefinição da esfera pública, além de uma discussão acerca dos processos de transformação em curso na esfera local de governo, particularmente no campo das políticas em saúde mental.

\section{Estado contemporâneo e políticas públicas no Brasil: novas formas de provisão de serviços públicos}

Deflagrada a grande crise dos anos 30, também chamada de Grande Depressão, tem-se um marco da crise do mercado e do Estado liberal, que passa a dar lugar a um novo formato, o do Estado do bem-estar social. Este assume, além de seus papéis específicos, a responsabilidade pela garantia e proteção dos direitos sociais à população e pela promoção do desenvolvimento no plano econômico e social do país, desempenhando um papel estratégico na coordenação da economia capitalista.

Surgem, então, o Estado do bem-estar nos países desenvolvidos, o Estado desenvolvimentista e protecionista nos países em desenvolvimento e o Estado comunista nos países com predomínio do modo de produção estatal (Pereira, 1997). Entendido como um modo particular de regulação social do Estado capitalista, expresso pela transformação das relações estatais com a economia e a sociedade - num dado período do desenvolvimento econômico -, o 
welfare state adquire diferentes formas, dependendo dos padrões específicos de intervenção estatal de cada país (Draibe, 1993).

No Brasil, as estruturas de intervenção estatal na esfera social têm sua gênese no pós-30, delineando-se de forma bastante peculiar em relação ao chamado Estado de bem-estar social dos países democráticos e capitalistas desenvolvidos. Cristaliza-se no país um modelo centralizador e pseudo-racionalizador, alheio às necessidades e reivindicações da população (Bodstein, 1993). Draibe (1993) o enquadra na categoria de meritocrático-particularista, com conotações corporativistas e clientelistas - a exemplo da política privatizante da Previdência Social -, mesmo que o sistema brasileiro de políticas públicas tenha adquirido outras características importantes no decorrer dos anos 70. A partir dessa década, em face do processo de globalização e desenvolvimento tecnológico, esse modelo centralizador e intervencionista - nomeado keynesiano - dá mostras de esgotamento e distorção perante as exigências que vão surgindo e entra em crise. Esta se manifesta no plano fiscal, no modo de intervenção na esfera socioeconômica e na superação da forma burocrática de administrar (Rietra, 1999).

Nesse cenário, ao final dos anos 70 e início dos 80 , o tema da natureza, do alcance e dos limites da intervenção estatal ganhou prioridade na agenda dos governos, destacando-se a redefinição dos novos níveis de intervenção governamental, bem como das diferentes formas de prover políticas públicas, em particular na área social. Nesse sentido, as respostas à crise de caráter mundial variaram de acordo com a posição ideológica de cada grupo. Disputaram espaço o ideário neoliberal - de 'desmantelamento' do Estado, com a idéia de 'Estado mínimo', isto é, da redução de seu papel em favor do mercado - e a abordagem de uma reforma da ação estatal, que passou a concentrar atenção na reforma propriamente, sendo controversa a perspectiva minimalista.

Surge um intenso debate em relação à crise do Estado e à necessidade de reformá-lo, que culmina, no Brasil dos anos 90, com a formulação do Plano Diretor da Reforma do Aparelho do Estado. Este definia objetivos e estabelecia diretrizes para a reforma da admi-nistração pública brasileira (Brasil, nov. 1995), compondose de quatro processos básicos: (1) a delimitação das funções do Estado, de modo a reduzir o seu tamanho em termos de pessoal, por meio de programas de privatização, terceirização e publicização; (2) a redução do grau de intervenção do Estado na economia, concebido agora como promotor da capacidade de competição do país em nível internacional; (3) o aumento da governança do Estado, isto é, da sua capacidade de tornar efetivas as decisões do governo; e (4) o aumento da governabilidade, no sentido de abertura de espaço social, aperfeiçoamento da democracia representativa (Pereira, 1997). 
Nessa reforma é possível identificar uma lógica de distinção entre espaço privado e público e, neste último, a diferenciação entre espaço estatal e o não-estatal. Três mecanismos fundamentais de controle são considerados: o Estado, o mercado e a sociedade civil (Pereira, 1997). Tais transformações apontam para a tendência de emergência de um 'terceiro setor', cenário que subjaz à crise do welfare state. Tal setor, por sua vez, não estaria sob o jugo nem do Estado nem do mercado, tendendo a ser reconstituído e sedimentado no próprio seio da sociedade organizada (Souza, 1997).

Identifica-se, portanto, a estruturação de um sistema mais complexo de gestão e do processo decisório, tendo a descentralização como um de seus componentes centrais, à medida que passa a envolver número cada vez maior de esferas e níveis de governo, mesclando organizações societais de diferentes naturezas com o poder público. Configuram-se novas formas de articulação entre Estado, sociedade civil e setor privado, para garantir a provisão dos serviços públicos, ficando a cargo do Estado a regulação "das relações contratuais ou das concessões aos agentes não estatais de atividades de interesse ou relevância pública" (Rietra, 1999, p.19).

Desse prisma, promove-se a expansão da capacidade de intervenção dos governos locais, de modo que se configurem como executores, a um só tempo, das políticas estatais - mediante planos e programas nacionais - e de interesses locais. Engendram-se mudanças significativas no desenho das políticas implementadas, tais como: (1) a tendência à promoção de ações integradas entre diversos órgãos e secretarias, direcionadas a um mesmo público-alvo, de forma a integrar diferentes setores na prestação de serviços; (2) o estabelecimento de parcerias com outras esferas de governo e com governos de outros municípios, havendo uma co-responsabilização pelas políticas e seus resultados; e (3) novas formas de articulação entre Estado, sociedade civil e mercado, desencadeando a inclusão de novos atores na formulação e implementação das políticas públicas no nível local (Farah, abr. 2000).

No entanto essa "descentralização de corte municipalizante acarretou a indefinição das competências e atribuições dos estados, criando um vazio no que se refere a medidas que atenuem as desigualdades regionais" (Monnerat, Senna, Souza, 2002, p.511), visto que o deslocamento de iniciativas de políticas públicas para as esferas subnacionais de governo não é um processo isento de problemas.

Nessa nova formatação, promovida pela reforma do aparelho do Estado, destaca-se a construção de novos arranjos envolvendo articulações intersetoriais, intergovernamentais, além de articulações entre Estado, mercado e sociedade civil para provisão de serviços públicos. "Esta nova governança - em construção - supõe mecanismos de interlocução com diversos atores e a consolidação de parcerias" (Farah, abr. 2000, p.28). 


\section{Novas formas de gestão: parcerias como instrumento de execução de políticas públicas}

Com base em críticas ao modelo de administração burocrática que aponta o aumento dos custos, a baixa qualidade e a ineficiência dos serviços sociais prestados à população - surgem inovações no modelo de gestão nas esferas federal, estadual e municipal. Rietra (1999), embora reconheça a diversidade dessas modalidades, destaca duas tendências: uma que procura esgotar as possibilidades de flexibilizar e aumentar o desempenho organizacional sem, no entanto, promover uma ruptura com a gestão burocrática, o que lhe confere limites, sobretudo no plano jurídico; e outra, que concede ao Estado o papel regulatório, deslocando para o setor público nãoestatal ou para o setor privado a prestação de serviços. Entre tais tendências, destacaremos a formação de parcerias envolvendo Estado e sociedade civil, em que ao primeiro atribui-se a responsabilidade de subsidiar os serviços prestados pela segunda. A diversidade de formatos que tal experiência assume faz emergir no cenário um amplo universo de possibilidades para a superação de problemas sociais, fundadas na aglutinação de esforços e na divisão de responsabilidades (Tenório, Rozenberg, jun. 1997).

Segundo Valarelli (1999), 'parceria' tem sido um termo bastante utilizado e difundido, buscando designar certas formas de cooperação entre organizações da sociedade que trabalham em uma ação conjunta, motivadas por interesses e objetivos partilhados. A intensificação do interesse e da concretização de parcerias entre o Estado e o terceiro setor tem em seu bojo a combinação dos seguintes fatores: a Constituição de 1988, que passa a prever a participação da sociedade civil na promoção de políticas sociais; as políticas macro-econômicas implementadas a partir de 1990, que aprofundaram problemas sociais e levaram à redução do gasto social nos níveis estadual e municipal; a reforma do Estado, que identifica o terceiro setor como potencial parceiro para atuar em áreas concebidas como não exclusivas do Estado; e o plano jurídico, tendo a legislação brasileira incorporado novas formas de promoção da participação das organizações sociais na implementação de políticas públicas (Reis, abr. 2000).

Nos referidos vínculos de parceria tende-se a uma co-responsabilização pela política e por seus resultados, mesmo que a cada um dos participantes caibam papéis diferenciados no processo de formulação, implementação e controle de políticas e ações públicas, tendendo a crescer a perspectiva de sustentabilidade das mesmas que, de outra forma, poderiam sofrer com a descontinuidade a cada mudança de governo (Farah, abr. 2000). Nesse cenário de uma nova governança, os governos locais têm assumido o papel de financiadores e reguladores de determinadas políticas públicas, cabendo ao terceiro setor a provisão dos bens e serviços à população local. 
Porém, cabe considerar que, mesmo que tal inovação tenha sido aceita pelos gestores, algumas questões devem ser problematizadas, a saber: (1) a reduzida experiência da administração pública no controle eficiente das organizações terceirizadas; (2) a baixa confiança na capacidade contratual do Estado; (3) a ameaça aos direitos dos cidadãos, no que concerne ao acesso e utilização de bens públicos, em virtude da criação de mecanismos alternativos para financiamento das organizações do terceiro setor; (4) a indefinição quanto ao responsável pelos altos custos do processo de estabelecimento da relação cooperativa; e (5) a evidência de que as concepções de mercado aplicadas ao setor público podem produzir resultados incertos e desastrosos, assim como desencadear novos gastos para correção das falhas do mercado (Rietra, 1999).

Nessa conjuntura de realocação e transformação de posições dos diferentes atores sociais perante as políticas e ações públicas, temse atribuído importância e visibilidade crescente às organizações do terceiro setor.

\section{Terceiro setor: a sociedade civil como parceira e agente de políticas públicas}

Na década de 1990, com a descentralização política, administrativa e econômica e com a busca de novas formas de gestão nos três níveis de governo, o terceiro setor passa a representar a promessa de renovação do espaço público, de maior eficiência e eficácia nos serviços prestados à população e de possibilidade de controle social em relação a políticas públicas e eficiência de gestão.

Na definição de Falconer (1999, p.2), "terceiro setor, no Brasil, é uma idéia-força, um espaço mobilizador de reflexão, de recursos e, sobretudo, de ação". A expressão vem se consolidando no vocabulário nacional e internacional para designar o conjunto de organizações e iniciativas oriundas da sociedade privada, voltadas à produção de bens e serviços públicos, visando ao desenvolvimento social, político e econômico de dada população (Fernandes, 1994).

Pereira e Cunill Grau (1999) identificam três vantagens primordiais no processo de articulação entre Estado e sociedade civil, para a provisão de serviços públicos: possibilidade de uma gestão mais flexível e desburocratizada; pluralização da oferta de serviços, sobretudo sociais; e responsabilização de dirigentes e participantes da organização. Apontam, ainda, a possibilidade de adaptação da prestação ao público-alvo, com base na produção de bens e serviços sociais, em contraposição às prestações uniformes que tendem a caracterizar o setor público-estatal. No entanto, salientam que o reconhecimento da importância do terceiro setor na produção de bens públicos não poderá direcionar-se a uma posição de negação do Estado. Nesse sentido, a transformação de serviços sociais esta- 
tais em públicos não-estatais não significa que o Estado deixa de ser responsável por eles; pelo contrário, o financiamento e o controle público estatal tornam-se cada vez mais necessários na produção dos bens coletivos, em uma quantidade desejável.

Nesse cenário de cooperação entre setor público não-estatal e setor público, torna-se necessária a elaboração de contratos/convênios firmados entre as instâncias envolvidas na parceria, como instrumento de acompanhamento permanente dessa relação. Isso propicia a descentralização na execução de projetos, atividades ou funções específicas fundadas em prioridades estratégicas, possibilitando, ao setor público não-estatal, o acesso a recursos orçamentários do governo federal e, ao Estado, o controle das ações desenvolvidas pelo primeiro (Falconer, 1999).

O contrato passa a ser elemento fundamental, constituindo um instrumento de accountability (responsabilização) das organizações, abarcando a especificidade da relação cooperativa. Nele deverão ser definidas as obrigações de cada parceiro, bem como os mecanismos institucionais de acompanhamento e avaliação do trabalho desenvolvido (Coelho, 2000). A relação cooperativa entre Estado e terceiro setor deverá estar inscrita em parâmetros claros de prestação de contas dos recursos envolvidos de controle sobre o emprego de recursos. Ela deverá ser firmada sob a égide de uma política social explícita, isto é, com metas claras a serem alcançadas.

Embora haja argumentações controversas sobre os significados e efeitos da participação do terceiro setor na provisão de bens e serviços à população, Abreu Mendes (jul.-set. 1999) destaca que ele tem sido apontado como orientação estratégica nacional, em razão da sua capacidade de assumir responsabilidades, gerar projetos, empreender iniciativas e mobilizar recursos para o desenvolvimento social do país. Em meio a essa problemática sobre a participação da sociedade civil na provisão de serviços públicos, verifica-se a tendência das reformas nas políticas e ações em saúde em curso no Brasil, nas últimas décadas.

No campo da saúde mental, mais especificamente naquele dos 'serviços residenciais terapêuticos', destaca-se a portaria 106 do Ministério da Saúde, de 2000, que abre a possibilidade de parcerias ao estabelecer, no artigo 5o, que "a critério do Gestor municipal/ estadual de saúde, [serviços residenciais terapêuticos] poderão funcionar em parcerias com ONGs de saúde, ou de trabalhos sociais ou de pessoas físicas" (Brasil, 2000).

\section{Descentralização e inovações na gestão: a reorganização do sistema de serviços de saúde}

No contexto de crise e reforma do Estado, o setor de saúde é particularmente afetado, "já que se define ... uma nova agenda, em 
que o tema da reforma setorial e da racionalização do gasto público ganha visibilidade crescente" (Souza, Bodstein, jan. 2002, p.482). No Brasil, ao debate da agenda de reforma do Estado em seus aspectos fiscais, político e administrativo somaram-se fatores internos, isto é, o legado institucional deixado pela Constituição Federal de 1988, que determinou a implantação do Sistema Único de Saúde (SUS) (Costa, jun. 2002).

A Constituição Federal de 1988 estabeleceu um novo modelo da política de saúde no Brasil. Ao distinguir e separar, definitivamente, as áreas de saúde e de previdência, rompeu com o modelo anterior, no qual se atribuía ao Ministério da Saúde a responsabilidade pelo combate às epidemias e ao Ministério da Previdência e Assistência Social, a assistência médica propriamente - clínica -, prestada a categorias profissionais específicas. Somente a partir de 1988 a Previdência Social perdeu suas atribuições de atendimento médico-hospitalar, passando a restringir-se à concessão e ao gerenciamento de aposentadorias, seguros de acidentes de trabalho e pensões (Costa, jun. 2002).

Há controvérsias em relação ao grau de ruptura do SUS com o padrão de intervenção estatal no campo social, implantado no Brasil pós-30. Alguns defendem a idéia de que houve ruptura com o modelo anterior, moldado a partir da década de 1930 por uma ló-gica contributiva (Costa, jun. 2002). Outros acreditam que a Constituição de 1988 trouxe não apenas uma interrupção, mas um retrocesso no processo de construção de um projeto de proteção social para o Brasil, e alegam que esse "projeto inscreveu a Saúde no marco de uma seguridade social pública, universal, garantidora de direitos de cidadania e que não tergiversava acerca da responsabilidade do Estado na sua implementação" (Noronha, Soares, 2001, p.446). E ainda há quem negue mudanças no curso da política de saúde pública no Brasil: "As inovações conceituais e organizatórias que apareceram na Carta não expressavam nenhuma ruptura com quaisquer dos interesses que incidiram sobre a arena setorial nessas décadas" (Costa, set.-dez. 1996, citado em Costa, jun. 2002, p.53).

Medici (1995) delineia três relevantes inovações, no âmbito da política de saúde, com a implantação do SUS: a definição de um comando único para o sistema de saúde em cada esfera de governo; a descentralização como pressuposto organizador básico, no qual a prestação dos serviços de saúde passa a ser, por excelência, responsabilidade de estados e municípios; e a co-responsabilização no financiamento dos recursos entre União, estados e municípios.

Fundamentado no pilar estrutural da descentralização - orientada pelas Normas Operacionais Básicas (Nobs-SUS), portarias do Ministério da Saúde que funcionam como instrumentos de regulação do processo de descentralização - e destacando divisão de respon- 
sabilidades, relação entre gestores e critérios de transferência de recursos orçamentários federais para estados e municípios, o SUS passa a ser concebido como estratégia adequada na administração e no controle dos gastos públicos, assim como um caminho para a redemocratização do sistema e a participação popular.

Essa política de descentralização orienta-se pela municipalização da saúde, trazendo inovações mediante a redefinição do processo decisório. Entram em cena os gestores locais, que se tornam atores fundamentais no campo da saúde, sendo considerados responsáveis diretos pela programação, execução e avaliação da rede de serviços e pela própria implementação do SUS, no nível local (Souza, Bodstein, jan. 2002). Porém esse deslocamento do processo decisório para o município acaba por gerar efeitos não previsíveis e, portanto, "uma reforma setorial cujo conteúdo, alcance e implicações são ainda de difícil avaliação" (p.482).

Embora haja um relativo consenso a respeito dos avanços promovidos pela descentralização no campo da saúde, esse conceito, considerado no âmbito do movimento de reforma sanitária brasileira, não se restringe à transferência de serviços e responsabilidades da esfera federal às estaduais e municipais. Ultrapassa-a, vinculando-se de forma estreita à estratégia de redemocratização e incorporação de novos atores sociais na construção de uma rede relacional interinstituições, em interníveis de governo e interserviços (Levcovitz, Lima, Machado, 2001). Compreende-se, portanto, que o processo de descentralização por si só não garante democracia no processo decisório.

Como desdobramento da consolidação do processo de descentralização, experiências locais têm apontado a promoção de diversas modalidades de gestão e controle de bens e serviços prestados pelas estruturas conveniadas, tanto da iniciativa privada como do terceiro setor. Novas modalidades de relação entre público e privado surgem na cena setorial, assim como nas relações de parceria entre as instâncias públicas. Destacam-se, ainda, os novos arranjos entre o público estatal e o não-estatal no âmbito das políticas públicas de saúde. Relações de parceria e cooperação entre as duas instâncias se estabelecem em nível local, configurandose importante estratégia na provisão e gestão de serviços prestados à população.

Apesar da reforma no sistema público de saúde, algumas observações devem ser feitas sobre o quadro conjuntural dessa área, nos anos seguintes à sua reorganização. Medici (1995) aponta as seguintes características: desorganização e sucateamento do sistema público de saúde de modo acelerado; declínio dos gastos com programas sociais, incluindo as vigilâncias sanitária, epidemiológica e a Fundação Nacional de Saúde; e forte crescimento do setor privado complementar. Sugere-se, assim, que nos anos 90 a concretização 
dos princípios do SUS esteve em contínua tensão, provocada por uma diversidade de obstáculos estruturais e conjunturais.

Seguindo essa lógica, embora a reforma da política de saúde no Brasil indique um inequívoco avanço, Draibe (1999) indica diversos problemas e desafios que se opõem ao aprofundamento da reforma, tais como: distorções e ineficiências do investimento, gerando implantação incompleta de redes intermediárias e básicas de serviços, o que vem sobrecarregar e comprometer a efetividade do sistema hospitalar; ineficiência, sobretudo de recursos; modelo assistencial baseado na livre demanda, no qual os princípios de adscrição de clientela e de identificação de porta de entrada estão ausentes; arcaica e inadequada organização e gestão do sistema, bem como de suas unidades organizacionais.

Como se percebe, no contexto de novos delineamentos das políticas públicas, particularmente no campo da saúde, a discussão sobre a temática do governo local/municipalização ganha destaque. De um lado, aponta-se o risco de clientelismo em relação aos atores e interesses tradicionais locais, pelo qual a descentralização pode ter pouco impacto nos indicadores de oferta e acesso aos serviços. De outro, o caráter positivo, a busca de novos arranjos e relações e maior responsabilização pela implantação e manutenção da rede de serviços, entre outros. Mas o que se vem destacar é que os gestores municipais, em alguns casos, devem buscar estratégias para a formulação, implementação e controle das políticas de saúde, de modo a auxiliar na solução de dificuldades, bem como na obtenção de resultados positivos. Nesse sentido, torna-se imperativa a análise de realidades concretas para que, com base nelas, se estabeleçam mediações eficazes para o entendimento e avaliação das relações entre Estado, sociedade civil e mercado e das políticas e ações em saúde, no contexto da atual descentralização do Estado brasileiro. Nessa linha se insere este artigo, ao abordar a relação de cooperação entre o gestor público e uma instituição do terceiro setor na construção e gestão de residências assistidas no município de Barbacena, como estratégia de desinstitucionalização no contexto da reforma psiquiátrica brasileira.

\section{Da 'nau dos loucos' ao 'trem de doido': a assistência psiquiátrica no município de Barbacena}

Promulgada pelo governo do estado de Minas Gerais em 1900, a lei 290 instituiu - na esfera de responsabilidade do Estado - a assistência aos alienados. Após sua regulamentação, designou-se a cidade de Barbacena como local para a instalação de tal assistência e, em 1903, surgiu o Hospital de Assistência a Alienados, nas dependências de um antigo sanatório (destinado à internação de tuberculosos), que havia sido fechado por motivo de falência. A nomea- 
ção de Barbacena - terra de políticos influentes - como local de referência à assistência aos alienados do estado relaciona-se à dinâmica da singular política mineira (Magro Filho, 1992). Em entrevista ao repórter Hiram Firmino, o doutor Jose Theobaldo Tollendal, à época (1982) diretor da instituição, afirmava: "Este hospital foi criado em Barbacena por questões meramente políticas. Jamais foi considerado o aspecto médico-terapêutico desta cidade ... eles preferiram aqui, por meros interesses pessoais"' (Firmino, 1982, p.56).

Pouco a pouco, a situação do Hospital-Colônia de Barbacena ia se tornando pior e, na década de 1950, caracterizava-se por pavilhões em ruínas, superlotação (em torno de 300 a 400\% superior a sua capacidade), precárias situações sanitárias dos internos, insolvência financeira e alto índice de mortalidade, sobretudo por diarréia. Entregues ao abandono médico, social e político, cerca de sessenta mil pessoas morreram sem a assistência devida nesse hospício, que se tornou, por décadas, um dos maiores fornecedores de cadáveres para as faculdades de medicina do país (Magro Filho, 1992). Assim se configurou a loucura na história de Barbacena, que se tornou referência no setor psiquiátrico estadual e nacional, alcançando repercussão internacional. Por sediar um hospital público de grande porte - o Centro Psiquiátrico de Barbacena - e mais quatro hospitais privados, o município chegou a ser conhecido, na década de 1970, como a cidade da América Latina com maior número de leitos psiquiátricos, daí a denominação 'cidade dos loucos'.

Em 1961 o hospício de Barbacena foi revelado ao país por denúncias veiculadas pelo Diário da Tarde, de Belo Horizonte (MG), gerando uma reação inesperada da opinião pública brasileira - alguns segmentos manifestaram, inclusive, oposição à continuidade das reportagens. Mesmo com tais apontamentos, as idéias de mudança só começaram a ecoar em 1979, com a presença de Basaglia e de Castel em debates no Brasil. Nesse ínterim houve renovação das denúncias e apresentação de propostas de reformulação da política de saúde mental, com menção especial ao Hospital-Colônia de Barbacena, na época comparado a um campo de concentração por Franco Basaglia, após visita à instituição.

A partir de então ocorreram conquistas significativas no campo da assistência psiquiátrica em Minas Gerais, com a criação do Projeto de Reestruturação da Assistência Psiquiátrica Pública no Estado. Em Barbacena, em 1985-1986 houve mudanças na estrutura físico-funcional do Hospital-Colônia - renomeado Centro Hospitalar Psiquiátrico de Barbacena (CHPB) -, em um processo de humanização da instituição que incidiu na área assistencial (Resgalla, 2003). Porém, em sua singularidade no campo da assistência psiquiátrica, o município conservou o modelo hospitalocêntrico e o paradigma psiquiátrico como norteadores de sua política. Com ações caracterizadas pela ausência de normatização e 
critérios de regulação, manteve internações abusivas, tempo médio de internação extenso e, conseqüentemente, práticas consideradas violentas para os pacientes.

No decorrer da década de 1990, a partir da elaboração de portarias ministeriais que instituíram e regulamentaram os 'serviços substitutivos em saúde mental' - em especial as portarias 106/00 e 1220/ 00 , que regulamentaram os 'serviços residenciais terapêuticos' -, a questão deixou de ser a humanização dos hospitais psiquiá-tricos; em seu lugar, propunha-se a sua substituição gradativa por novos serviços, adoção de estratégias sanitárias e dispositivos sociais. A proposta tornou-se viável graças à conjuntura local, ou seja, quando um grupo do poder municipal se mobilizou e operacionalizou a reforma psiquiátrica. Tal processo foi sustentado pelo então secretário de Saúde e por agentes locais em saúde mental, com o apoio do governo municipal, apesar da oposição e resistência de outros atores, para quem a reestruturação colocaria em risco a hegemonia do saber e/ou o capital advindo da 'indústria da loucura'.

\section{Reforma psiquiátrica em Barbacena: desafios e (re)construção do cotidiano}

Para a construção de um outro modelo de assistência à saúde mental em Barbacena, inicialmente realizou-se um trabalho de censo e mapeamento da população interna nos cinco hospitais psiquiátricos do município, assistidos pelo SUS. A partir de tal levantamento e com base no que havia sido 'descoberto' - a situação extrema de abandono em que se encontravam os internos: sem vínculos familiares, documentos ou benefícios previdenciários e submetidos a longo tempo de internação -, inicia-se a criação do projeto em saúde mental de Barbacena, norteado pela construção de uma rede de substituição ao hospital psiquiátrico, efetiva e resolutiva. Ele foi apresentado e aprovado pelo gestor e Conselho Municipal de Saúde do município.

Barbacena ainda conta com quatro hospitais psiquiátricos, um deles na rede pública e os demais conveniados com o SUS. Em 2001, antes da implantação do projeto, o município contava com 1.336 leitos; hoje tem seiscentos leitos credenciados pelo SUS (Lobo, Alvarenga, Fassheber, 2004). Tais dados apontam um processo de consolidação da reforma psiquiátrica, com a implantação de uma rede substitutiva dos hospitais psiquiátricos, além de um trabalho de mudança cultural em relação à loucura e ao 'louco', no qual estão inseridos o poder público local, o ministério público e a Igreja.

Como ponto de partida e consolidação do processo de reforma psiquiátrica no município, optou-se pela construção de um Centro de Apoio Psicossocial municipal como serviço de porta de entrada, funcionando diariamente 12 horas durante toda a semana, com 
leitos de observação e retaguarda noturna. Inaugurado em março de 2002, o Caps Municipal (Caps II) passa a funcionar como a instância responsável por internações e avaliação de solicitações de renovações de Autorizações de Internação Hospitalar (AIHs). Trata-se, portanto, de uma central de regulação de leitos psiquiátricos e de atendimento a emergências psiquiátricas, contando com oito leitos de retaguarda. Após sua implantação, obteve-se uma redução significativa no número de internações: de 130 para dez a 13 por mês (Lobo, Alvarenga, Fassheber, 2004), configurando-se importante dispositivo assistencial voltado para atenção integral, um espaço de acolhimento e cuidados em saúde mental, além de supervisor hospitalar do sistema.

Trabalhou-se, também, na reestruturação do antigo Núcleo de Estudos e Prevenção ao Alcoolismo (Nepa), que passou a se constituir como Hospital-Dia Álcool e Droga (AD), unidade substitutiva que também acusa indicadores significativos na redução do número de internações por uso de álcool e drogas - de quarenta para oito internações por mês (Lobo, Alvarenga, Fassheber, 2004).

No caso das emergências psiquiátricas noturnas, o município passou a contar com o serviço do Pronto Socorro Municipal que, na nova configuração da Rede de Saúde Mental, em funcionamento a partir de novembro de 2004, assumiu importante papel ao atuar como responsável pelas emergências relativas a álcool e drogas (Lobo, Alvarenga, Fassheber, 2004). Além disso, o ambulatório do CHPB foi parcialmente integrado à rede, com base em uma reestruturação de seu papel, como acolhimento e encaminhamento do usuário ao tratamento adequado.

Considerando a eventual necessidade de internação, o município conta com 24 leitos para internação integral, na unidade de agudos do CHPB. Importante avanço para um hospital público, por romper com o abusivo e arbitrário uso dos hospitais psiquiátricos privados. No entanto, até o momento, conta-se apenas com leitos destinados ao sexo masculino e, por esse motivo, no caso de internações femininas ainda se utiliza a rede privada, mesmo que de maneira regulada.

Implantado em 2003, o Centro de Convivência - espaço de circulação destinado não apenas aos usuários da saúde mental, mas a toda a comunidade - constitui importante dispositivo social na reforma psiquiátrica do município. O Centro vem apresentando uma média mensal de freqüência de 370 pessoas, das quais $70 \%$ da comuni-dade e 30\% de usuários da rede em saúde mental (Lobo, Alvarenga, Fassheber, 2004). Funcionam ali diversas oficinas terapêuticas e de trabalho, cujo objetivo é propiciar um espaço privilegiado de construção de subjetividades e, ao mesmo tempo, de reinserção social de pessoas marginalizadas por meio da promoção do aspecto comunitário. 
Atualmente são vinte as residências assistidas - construídas a partir da des-hospitalização de internos de todos os hospitais psiquiátricos do município - totalizando 150 pacientes egressos de hospitalização crônica, que se encontram em deflagrado processo de reabilitação psicossocial. Na manutenção desses dispositivos, a Prefeitura de Barbacena conta com apoio do Instituto José Luís Ferreira, instituição filantrópica, sem fins lucrativos, ligada à Arquidiocese de Mariana (MG). Essa cooperação é o objeto de estudo deste trabalho. Nesse processo de dês-hospitalização e desinstitucionalização, cabe destacar o retorno à estrutura familiar - com suporte assistencial - de oito pessoas que se encontravam internadas, em situação asilar, em hospitais psiquiátricos do município.

Ainda no campo assistencial, encontra-se em processo de desenvolvimento, a partir de agosto de 2004, a integração da equipe e ações da saúde mental ao Programa de Saúde da Família (PSF), tendo por objetivo o fortalecimento da proposta de territorialidade para as residências assistidas, bem como para o PSF, além de uma ampliação de sua clínica.

Apesar de todos esses avanços da reforma psiquiátrica em Barbacena, cumpre enfatizar a necessidade da criação de um projeto municipal de maior amplitude, para que seja possível o atendimento às diversas demandas em saúde mental. Nessa perspectiva, aponta-se a necessidade da construção de serviços, dispositivos e estratégias direcionadas às crianças e adolescentes. Sabemos, entretanto, que esse é um percurso que se desenvolve e amadurece a passos lentos.

Feitas tais exposições e ressalvas, destaca-se que o processo de reforma psiquiátrica em Barbacena, norteado pela desinstitucionalização, não se restringe à mera des-hospitalização e à construção de uma rede de atenção substitutiva do hospital psiquiátrico, tampouco significa desassistência. Trata-se, antes, de reformulações, de um processo de construção de uma nova realidade em torno da loucura e do paradigma psiquiátrico, para o qual convergem recursos sanitários (serviços de saúde), econômicos (bolsa auxílio-reabilitação, previdência), afetivos (relações pessoais, vizinhança, familiares etc.) e culturais (Brasil, 2004) - um trabalho de desconstrução e (re)invenção do cotidiano, das mentalidades e da cultura barbacenense, profundamente enraizados no modelo manicomial.

\section{A experiência de cooperação entre poder público e terceiro setor na reforma psiquiátrica}

Em vista da necessidade de se criarem mecanismos de divulgação das iniciativas em curso, bem como da importância da análise de novos arranjos de gestão no campo da saúde mental, serão apon- 
2 Pessoas que possuem conhecimentos especiais sobre a temática estudada e estão interessadas em compartilhar seus conhecimentos com o pesquisador (Tobar, Yalour, 2001). tadas algumas linhas de reflexão com base nas questões abordadas ao longo deste estudo, na tentativa de assinalar aspectos relevantes da experiência cooperativa entre gestor público e terceiro setor na reforma psiquiátrica de Barbacena.

Este trabalho examinou, valendo-se de entrevistas de informantes-chaves ${ }^{2}$ e de pesquisa documental, inovações na modalidade de gestão em saúde mental no município de Barbacena, que passou a contar com a participação de uma instituição do terceiro setor no trabalho referente aos dispositivos residenciais 'terapêuticos'. Para entrevista foram considerados informantes-chaves dois técnicos da Coordenação de Saúde Mental, vinculados ao Departamento Municipal de Saúde Pública (Demasp), e três funcionários do Instituto José Luiz Ferreira, também de Barbacena.

Acena-se, mediante o exposto, com uma alternativa para reorganização da intervenção estatal na produção e execução de serviços de caráter público, isto é, uma estratégia de realização do projeto de desinstitucionalização, no contexto da reforma psiquiátrica em curso no município. Portanto essa experiência de cooperação faz parte de um processo de articulação do Estado com o terceiro setor, no qual se observa uma tendência à inclusão de novos atores na formulação e implementação das políticas públicas em nível local, para provisão e gestão de serviços. Mais especificamente, o presente estudo explora esse novo arranjo em relação ao trabalho de residências assistidas no campo da saúde mental, na cidade de Barbacena.

No caso em análise, o gestor público permaneceu responsável pela esfera assistencial e financeira do projeto, optando por flexibilizar a gestão administrativa das residências assistidas. Diante de uma série de dificuldades e limitações do poder público local perante o projeto de implantação e gestão das residências assistidas que se configuravam até mesmo como entraves significativos e ameaçadores ao desenvolvimento do projeto -, a cooperação entre gestor público e terceiro setor abriu um novo e amplo universo de possibilidades para a superação dos problemas, com base na aglutinação de esforços e na divisão de responsabilidades entre as duas instâncias.

Um fator de extrema relevância na experiência de cooperação estudada diz respeito à sua legalidade e legitimidade. Primeiramente por se tratar de um convênio celebrado entre a Prefeitura Municipal de Barbacena, através de seu Departamento de Saúde Pública, e uma instituição filantrópica de reconhecimento federal, estadual e municipal, o Instituto José Luiz Ferreira. O convênio foi aprovado pelo Conselho Municipal de Saúde e pela Câmara Municipal de Barbacena. Em segundo lugar, por ser um instrumento da accountability das instâncias envolvidas, visto que contempla mecanismos institucionais de responsabilização, com 
normas e regras claras que definem responsabilidades e direitos de cada um dos parceiros.

Como desdobramento de um processo de conhecimento mútuo, ou seja, de identificação e avaliação dos objetivos institucionais, das dinâmicas de trabalho e da capacidade gerencial e financeira de cada parceiro, elaborou-se um 'contrato' de cooperação - convênio 03/2003 (Carvalho, set. 2003) -, no qual se definiram objetivos, obrigações e responsabilidades de ambas as partes; os recursos disponíveis para a implantação e manutenção das residências assistidas; as metas do projeto; e o mecanismo de avaliação do trabalho desenvolvido. Tem-se, pois, como uma das suas finalidades o fortalecimento da supervisão, o controle e a avaliação por parte do poder público local sobre os resultados da relação de cooperação firmada, bem como a facilitação do processo de gerenciamento/administração do projeto pela instituição conveniada. Acrescente-se, ainda, a possibilidade de um controle social sobre objetivos, metas e resultados do projeto. Esses são fatores propulsores de uma ação conjunta, em benefício dos cidadãos para os quais se destinam os dispositivos residenciais assistidos.

Porém, embora haja uma cláusula $\left(11^{\text {a }}\right)$ referente à rescisão do convênio por decisão de uma das partes ou por inadimplemento de uma das cláusulas, não se estabeleceram penalidades caso isso venha a ocorrer - aspecto este relevante num 'contrato', visto que, para a responsabilização da cooperação, além das necessárias definições em termos de atribuições de cada parceiro e variáveis de acompa-nhamento, controle e avaliação do trabalho realizado, é necessária, ainda, a definição de punições em caso de não cumprimento das cláusulas.

Foi possível identificar, segundo os entrevistados, quatro grandes vantagens: (1) maior flexibilidade da gestão, o que permitiu resolver mais facilmente os problemas enfrentados pelo poder público local no projeto de desinstitucionalização, mas com a manutenção da prática e do controle da assistência em saúde mental aos moradores das residências atendidas pela equipe técnica do município; (2) maior agilidade no processo; (3) garantia de certo grau de sustentabilidade do projeto, por se tratar de uma instituição do terceiro setor, tradicional e controladora de ações sociais; e (4) a aproximação e o entendimento da comunidade barbacenense em relação ao projeto de desinstitucionalização no âmbito da reforma psiquiátrica, o que proporcionou até mesmo uma mudança no relacionamento da sociedade com as residências assistidas e seus moradores.

Essa gestão flexibilizada inscreve-se na esfera de descentralização administrativa, com a instauração de novos arranjos na relação entre Estado e sociedade civil no caso considerado, isto é, no gerenciamento das residências assistidas. Delineou-se, com base nisso, como uma delegação de responsabilidade ao terceiro setor no sen- 
tido de transferência de responsabilidades administrativas, o que não veio a significar uma omissão do poder público local, uma vez que o convênio tem se configurado como uma agregação de instrumentos e estratégias para otimização dos objetivos e metas do projeto de desinstitucionalização, no âmbito da reforma psiquiátrica do município. Nesse sentido, cabe ao poder público local a responsabilização da gestão, garantindo o cumprimento dos termos do convênio e a qualidade da assistência oferecida aos moradores das referidas residências. Portanto nesse novo vínculo de cooperação há uma co-responsabilização pela política, por ações e resultados em saúde mental, mesmo que a cada um dos parceiros caibam papéis diferenciados na implantação e gestão das casas assistidas.

Cumpre ressaltar que o poder público mantém a responsabilidade assistencial, financeira e regulatória pelo projeto, aspecto relevante para o sucesso da experiência porque, para a co-responsabilização entre as duas instâncias envolvidas na relação cooperativa, é preciso que se garantam as condições necessárias para a realização do projeto, a exemplo do repasse orçamentário para o Instituto José Luiz Ferreira, que tem sido realizado satisfatoriamente pelo município, segundo depoimentos dos entrevistados. Ainda sobre essa questão, cabe frisar que a preocupação em criar indicadores, mecanismos de regulação do convênio e uma planilha de custos aponta a aceitação dos pressupostos de responsabilização, determinando, dessa forma, a busca de transparência e de indicadores de desempenho do trabalho desenvolvido em cooperação. Demonstra, também, uma mudança em relação ao modelo de administração burocrática, em que são escassos os mecanismos de responsabilização, acompanhamento e avaliação de desempenho, considerado norma institucional.

Importante fator nessa cooperação diz respeito ao mecanismo de sustentação/acompanhamento do convênio, bem definido e esclarecido no documento que legaliza a cooperação - convênio 03/2003 (Carvalho, set. 2003) -, em que uma das cláusulas estabelece a prestação trimestral de contas do Instituto José Luiz Ferreira ao município, o que vem somar ao acompanhamento, por parte do poder público, do trabalho desenvolvido. É igualmente importante frisar que a instituição escolhida passou por um processo de avaliação que resultou no aumento de sua credibilidade institucional e na consolidação de sua idoneidade, o que tem produzido, no âmbito do projeto, resultados favoráveis.

Tais elementos de acompanhamento e avaliação de resultados servem ainda à necessidade de justificar, perante a sociedade, a razão da existência e a legitimidade desse convênio. Isso se pode verificar nos depoimentos dos entrevistados, que estabelecem comparações entre dois momentos distintos no contexto da implantação e gestão das residências assistidas, o antes' e o 'depois' do convênio. 
Nessa perspectiva, a forma de acompanhamento e avaliação mais constante, feita em conjunto pelo poder público e pela referida instituição do terceiro setor, foi identificada em várias entrevistas, especialmente através de reuniões realizadas com os profissionais das duas instituições, bem como com os 'cuidadores' e moradores das residências assistidas, tendendo a ser uma avaliação permanente, pautada na participação eqüitativa de todos os envolvidos no projeto de desinstitucionalização.

\section{Conclusão}

O presente estudo, de caráter exploratório, não propõe conclusões definitivas a respeito da cooperação entre gestor público e terceiro setor na construção e manutenção de residências assistidas em Barbacena, como estratégia no contexto da reforma psiquiátrica brasileira. Antes de tudo, é uma reconstrução da evolução da história da atenção psiquiátrica em um município do estado de Minas Gerais. Todavia, com base no exposto, aponta que a experiência de cooperação entre gestor público e terceiro setor na implantação e manutenção de residências assistidas, em Barbacena, tem indicado a tendência do poder público local a desenvolver ações comprometidas com os pressupostos da reforma psiquiátrica, propiciando agilidade e qualidade, bem como certo grau de sustentabilidade do projeto.

Essa sustentabilidade tende a aumentar com a participação de uma instituição do terceiro setor com credibilidade institucional, visto que, por meio de novos arranjos institucionais, tende a crescer a perspectiva de permanência dos dispositivos residenciais assistidos - que, de outra forma, poderiam sofrer com a descontinuidade na esfera pública. Torna-se, ainda, significativo o enraizamento das políticas em um espaço público que transcende a esfera estatal, o que repercute, e muito, na eficiência e efetividade da política implantada (Farah, abr. 2000). Diante disso, os informantes-chaves entrevistados acreditam que o trabalho desenvolvido possua certo grau de sustentabilidade, mesmo considerando uma eventual descontinuidade política provocada por mudanças de governo.

Em relação à dinâmica do convênio, tendo como parâmetro a análise das práticas discursivas dos entrevistados e do convênio 03/2003 (Carvalho, set. 2003), pode-se concluir que compete ao poder público local a responsabilidade pela assistência, pela seleção de recursos humanos, pelo repasse do valor correspondente ao acordado para manutenção das residências assistidas e pelo acompanhamento e controle do trabalho desenvolvido, ao passo que ao Instituto José Luiz Ferreira cabe o gerenciamento administrativo dessas casas, que devem seguir as orientações técnicas dadas por uma equipe de nível superior, especializada em saúde mental. 
Conforme verificado nas entrevistas realizadas e na análise do documento mencionado, o convênio tem produzido resultados positivos, como por exemplo a expansão do número das casas assistidas - e, conseqüentemente, o aumento do índice de des-hospitalização de pessoas -, bem como a facilitação para alugar casas e contratar fornecedores de gêneros alimentícios. Observa-se, ainda, uma contribuição para a mudança cultural na relação com a loucura e o 'louco'. Verificou-se, também, o investimento e o envolvimento de ambas as partes no projeto, bem como o comprometimento com a qualidade de vida dos moradores das residências assistidas.

Tal convênio, como estratégia de desinstitucionalização no contexto da reforma psiquiátrica, traduz-se em um marco para o processo no município de Barbacena. A participação de uma instituição do terceiro setor, sobretudo vinculada à Igreja Católica, na construção e manutenção de residências assistidas propiciou uma mudança cultural, por parte da comunidade barbacenense, em relação às casas e aos seus moradores. É importante considerar que a posição assumida pelos atores relacionados ao Instituto José Luiz Ferreira, na cooperação com o gestor público no projeto de residências assistidas, longe de configurar uma estratégia de captação de fiéis e de reprodução de abordagens típicas de uma instituição que produz a mortificação do sujeito, tem se orientado, como evidenciado nas entrevistas, para a promoção humana e social de pessoas anteriormente marginalizadas e rotuladas como 'loucas', encerradas em hospitais psiquiátricos. Dessa forma, a cooperação do Instituto José Luiz Ferreira tem apontado a assertiva de Pereira e Cunill Grau (1999), segundo a qual, no século XXI, o setor público nãoestatal poderia se delinear como uma dimensão-chave da vida social.

A experiência, portanto, segue a tendência de inovação na modalidade de gestão do setor de saúde, indicando uma preocupação com a preservação das diretrizes básicas do SUS e, sobretudo, das diretrizes da reforma psiquiátrica. Tais fatores apontam uma experiência de cooperação que tem gerado bem público, ou melhor, dispositivos de promoção da vida de pessoas marginalizadas e discriminadas, propiciando-lhes o direito à cidadania e melhor qualidade de vida. Sua análise indica caminhos que seguem as propostas da reforma do Estado, quais sejam, a redução do seu tamanho e o fortalecimento de suas funções regulatórias, em detrimento de seu papel de executor de políticas públicas, além da conversão de uma administração burocrática em uma administração gerencial que, por ter um caráter mais flexível, atende de forma mais satisfatória aos interesses dos cidadãos-clientes.

Trata-se, dessa forma, de uma inovação institucional inscrita na esfera das políticas públicas no campo da saúde mental em Barbacena, com base no entendimento de que, no contexto estudado, há uma lógica de produção de bens coletivos que está se tor- 
nando viável por meio de uma experiência de cooperação entre poder público e terceiro setor. Dessa forma, o presente estudo termina com a perspectiva de que seja possível e benéfica a realização de mais pesquisas abarcando a experiência de cooperação entre poder público e terceiro setor no âmbito da reforma psiquiátrica, de modo a nortear outras experiências e processos e, ainda, auxiliar no reconhecimento de formas válidas de cooperação entre Estado e sociedade, diferenciando-as de experiências de simples cooptação ou de pseudoparticipação.

\section{BIBLIOGRAFIA}

Amarante, Paulo (Coord.)

1995

Bodstein, Regina Cele de Andrade (Org.)

1993

Brasil

Brasil

Brasil

nov. 1995

Carvalho, Nelma

Abreu de

set. 2003

Coelho, Simone de

C. Tavares

2000

Costa, Nilson do Rosário set.-dez. 1996

Costa, Ricardo C. Rocha da jun. 2002

Draibe, Sônia Miriam 1999

Draibe, Sônia Miriam 1993

Fagundes, Sandra 1992
Loucos pela vida: a trajetória da reforma psiquiátrica no Brasil.

2.ed. rev. e ampl. Rio de Janeiro: Fiocruz. 136p.

Serviços locais de saúde: construção de atores e políticas. Rio de Janeiro: Relume-Dumará.

Ministério da Saúde. Secretaria de Atenção à Saúde. Departamento de Ações Programáticas Estratégicas. Saúde mental no SUS: os centros de atenção psicossocial. Brasília: Ministério da Saúde.

(Série F. Comunicação e Educação em Saúde).

Ministério da Saúde. Legislação em saúde mental - 1990-2000.

Brasília: Ministério da Saúde.

Ministério da Administração e da Reforma do Estado. Câmara da Reforma do Estado. Plano diretor da reforma do aparelho do Estado. Brasília: Presidência da República.

Convênio, n.3, Barbacena.

Terceiro setor: um estudo comparado entre Brasil e Estados Unidos. São Paulo: Senac.

Inovação política, distributivismo e crise: a política de saúde nos anos 80 e 90. Dados, Rio de Janeiro, v.39, n.3, p.479-511.

Descentralização, financiamento e regulação: a reforma do sistema público de saúde no Brasil durante a década de 1990. Revista de Sociologia E Política, Curitiba, n.18, p.49-71.

As políticas sociais nos anos 1990. In: Baumann, Renato (Org.). Brasil: uma década em transição. Rio de Janeiro: Campus. v.1, p.101-42.

Brasil: o sistema de proteção social e suas transformações recentes. Santiago: Cepal. (Série Reformas de Políticas Públicas, 14)

Saúde mental coletiva: a construção no Rio Grande do Sul. In: Bezerra Jr., Bezerra; Amarante, Paulo (Org.). Psiquiatria sem hospício: contribuições ao estudo da reforma psiquiátrica. Rio de Janeiro: Relume-Dumará. p.57-68 
Falconer, André Pablo 1999

Farah, Marta F. Santos abr. 2000

Fernandes, Rubem

César 1994

Ferreira, Flávio; Inácio, José s.d.

Firmino, Hiram 1982

Levcovitz, Eduardo; Lima, Luciana D.; Machado, Cristiane V. 2001

Lobo, Renato L. L. de Castro; Alvarenga, Lys T. de; Fassheber, Vanessa B. 2004

Magro Filho, João Baptista 1992

Medici, André Cezar 1995

Mendes, Luiz Carlos A. jul.-set. 1999

Milagres, André Luís D. 2002

Monnerat, Giselle L.; Senna, Mônica de C. M.;

Souza, Rosimary G. de 2002

Noronha, José C. de; Soares, Laura $\mathrm{T}$. 2001

Pereira, Luiz C. Bresser 1997

Pereira, Luiz C. Bresser; Cunill Grau, Nuria (Org.) 1999
A promessa do terceiro setor: um estudo sobre a construção do papel das organizações sem fins lucrativos e do seu campo de gestão. São Paulo: Centro de Estudos em Administração do Terceiro Setor/ Universidade de São Paulo.

Parcerias, novos arranjos institucionais e políticas públicas locais. Cadernos Gestão Pública e Cidadania, São Paulo, v.18, p.1-33.

Privado porém público: o terceiro setor na América Latina.

Rio de Janeiro: Relume-Dumará.

Diário da Tarde. In: Magro Filho, João Baptista. A tradição da loucura: Minas Gerais 1870/1964. Belo Horizonte: Coopmed; Ed. UFMG. p.130-131.

Nos porões da loucura.

Rio de Janeiro: Codecri. (Coleção Edições Pasquim).

Política de saúde nos anos 90: relações intergovernamentais e o papel das Normas Operacionais Básicas. Ciência E Saúde Coletiva, Rio de Janeiro, v.6, n.2, p.269-291.

A construção de uma nova lógica assistencial e a consolidação do modelo da reforma psiquiátrica na Cidade das Rosas (jan. de 2001 a nov. de 2004). In: Relatório de Gestão em Saúde Mental. Barbacena, 31f.

A tradição da loucura: Minas Gerais 1870/1964.

Belo Horizonte: Coopmed; Ed. UFMG.

Saúde: modelos de gestão descentralizada. Alternativas para o Brasil. In: Velloso, João Paulo dos Reis; Albuquerque, Roberto C.; Knoop, Joachim (Coord.). Políticas sociais no Brasil: descentralização, eficiência e eqüidade. Rio de Janeiro: Fórum Nacional; Inae; Ildes; Fund. F. Elbert. p.91-147.

Estado e terceiro setor: uma análise de aproximação.

Revista do Serviço Público, Rio de Janeiro, ano 50, n.3, p.73-91.

Porta de saída do asilo: cotidiano, narrativa e subjetividade nas residências terapêuticas em saúde mental do IMAS Juliano Moreira. Dissertação (Mestrado em Ciências Sociais) - Universidade do Estado do Rio de Janeiro, Rio de Janeiro.

A reorganização dos serviços de saúde no cenário local. Ciência \& Saúde Coletiva, Rio de Janeiro, v.7, n.3, p.509-521.

A política de saúde do Brasil nos anos 90. Ciência \& Saúde Coletiva, Rio de Janeiro, v.6, n.2, p.445-450.

A reforma do Estado nos anos 90: lógica e mecanismos de controle. Brasília: Ministério da Administração Federal e Reforma do Estado (Cadernos Maré da Reforma do Estado, 1).

O público não-estatal na reforma do Estado. Rio de Janeiro: Fundação Getúlio Vargas. 
Reis, Liliane G. da Costa abr. 2000 Resgalla, Rosana Maria
2003

Rietra, Rita de Cássia P. 1999

Souza, Manoel T.A. de 1997

Souza, Rosimary G. de; Bodstein, Regina Cele de Andrade jan. 2002

Tenório, Fernando Guilherme out. 2002

Tenório, Fernando Guilherme; Rozenberg, Eduardo Jacob jun. 1997

Tobar, Federico; Yalour, Margot Romano 2001

Valarelli, Leandro Lamas 1999

Viana, Ana L. d’Ávila; Fausto, Márcia Cristina R.; Lima, Luciana D. de mar. 2003
Parceria com o Estado: problema ou solução para as organizações do terceiro setor? Disponível em: http://www.rits.org.br/acervo/ acervo_pesquisa_detalhe.cfm?CA=1636. Acesso em: set. 2004 .

A travessia do hospício para a residência terapêutica: a conquista de um porto seguro? Dissertação (Mestrado em Enfermagem) - Universidade Federal de Minas Gerais, Belo Horizonte.

Inovações na gestão em saúde mental: um estudo de caso sobre o Caps na cidade do Rio de Janeiro. Dissertação (Mestrado em Saúde Pública) Escola Nacional de Saúde Pública, Fundação Oswaldo Cruz, Rio de Janeiro.

Argumentos em torno de um 'velho' tema: a descentralização. Dados, Rio de Janeiro, v.40, n.3, p.377-411.

Inovações na intermediação entre os setores público e privado na assistência à saúde. Ciência E Saúde Coletiva, Rio de Janeiro, v.7, n.3, p.481-492.

Gestão pública ou gestão social? Um estudo de caso. In: Congresso Internacional del CLAD sobre la Reforma del Estado y de la Administración Pública, 7, Lisboa. p.8-11.

Gestão pública e cidadania: metodologias participativas em ação.

Cadernos Gestão Pública e Cidadania, São Paulo, v.7, p.1-35.

Como fazer teses em saúde pública: conselhos e idéias para formular projetos e redigir teses e informes de pesquisa. Rio de Janeiro: Fiocruz.

Parcerias. Disponível em:http://www.rits.org.br/acervo-d/parcerias.doc. Acesso em: set. 2004.

Política de saúde e eqüidade. São Paulo em Perspectiva, São Paulo, v.17, n.1, p.58-68. 